\title{
A Note on the 'Linsanity' of Measuring the Relative Efficiency of National Basketball Association (NBA) Guards
}

\author{
Boon L. Lee ${ }^{*}$ \\ School of Economics and Finance, Queensland University of Technology \\ Andrew C. Worthington \\ Department of Accounting, Finance and Economics, Griffith University
}

"A particular shot or way of moving the ball can be a player's personal signature, but efficiency of performance is what wins the game for the team.” Pat Riley (ex-Knicks, Lakers, and Heat coach)

\begin{abstract}
This note examines the productive efficiency of 62 starting guards during the 2011/12 National Basketball Association (NBA) season. This period coincides with the phenomenal and largely unanticipated performance of New York Knicks' starting point guard Jeremy Lin and the attendant public and media hype known as Linsanity. We employ a data envelopment analysis (DEA) approach that includes allowance for an undesirable output, here turnovers per game, with the desirable outputs of points, rebounds, assists, steals, and blocks per game and an input of minutes per game. The results indicate that depending upon the specification, between 29 and 42 percent of NBA guards are fully efficient, including Jeremy Lin, with a mean inefficiency of 3.7 and 19.2 percent. However, while Jeremy Lin is technically efficient, he seldom serves as a benchmark for inefficient players, at least when compared with established players such as Chris Paul and Dwayne Wade. This suggests the uniqueness of Jeremy Lin's productive solution and may explain why his unique style of play, encompassing individual brilliance, unselfish play, and team leadership, is of such broad public appeal.
\end{abstract}

JEL codes: D19, C61, M59.

Keywords: Data envelopment analysis, technical efficiency, basketball players.

\footnotetext{
* Corresponding author: School of Economics \& Finance, Queensland University of Technology, GPO Box 2434, Brisbane, QLD 4001, Australia. Email. bl.lee@qut.edu.au.
} 


\section{Introduction}

Jeremy Lin, New York Knicks starting point guard, Harvard economics graduate, and the first player of Taiwanese descent in the National Basketball Association (NBA), has thrilled the US and the world with an average of more than 27 points, 8 assists, and 2 steals per game in his first four starts. Leading his team to four successive victories in the 2011/12 season in his first week as starting point guard earned him Eastern Conference player of the week as well as two straight Sports Illustrated coversjoining the likes of Dirk Nowitzki of the Dallas Mavericks and Michael Jordan (former Chicago Bulls player) with dual distinctions. Dubbed Linsanity (currently with more than seven million Google hits), Lin has become a phenomenon since he made history by scoring 89 points in his first three starts. This is the most of any player since the NBA-American Basketball Association (ABA) merger in 1976/77, exceeding both LeBron James in his first three starts, and rivalling such legends as Michael Jordan and Larry Bird.

However, the fascination with Linsanity goes beyond mere playing statistics. Lin never received a basketball scholarship out of high school and went undrafted in the 2010/11 NBA draft. He was a benchwarmer in his previous teams, played minimal minutes, and was waived off the rosters of several teams after his first year in the NBA. Indeed, prior to the start of the 2011/12 season, Lin was playing in the NBA D-league. But since February 4, when he came off the bench and led New York to victory over New Jersey scoring 25 points and handing out 7 assists in 36 minutes of playing time, he has become the Knicks' starting point guard.

Linsanity has since moved beyond the basketball court into the world of business. Adubato (2012) at nj.com argues that leaders and professionals in all arenas can learn from Lin's can-do attitude, unselfishness, humility, and ability to recognize the achievements of his teammates. Gorrell (2012) in the Huffington Post maintains Lin's story is all about the importance of diversity in business and the infectious nature of success, while Crecenzo (2012) in Entrepreneur suggests “...the talent universe is full of overlooked people [like Lin], shunned for reasons of geography, status or background”. Lastly, Jackson (2012) in Forbes asserts that Lin's success is proof that it is “... always better to be a first-rate version of yourself, instead of a second-rate version of somebody else”, to believe in yourself, and to seize opportunity when it comes up.

Paradoxically, Lin is not without his critiques, as exemplified by Neil Paine at Sports Illustrated. Paine (2012), of course, lauds Lin’s “...phenomenal ability to get to the basket” and natural playmaking 
ability, maintaining that his “...quick first step and attacking style naturally lead to a large number of free throws, which are great for enhancing offensive efficiency":

[E]fficiency has definitely been the name of Lin's game during his recent run. His true shooting percentage, which measures the average number of points a player generates per possession when he shoots, compares favourably to that of other star players...only two players [Lakers' Kobe Bryant and the Thunder's Russell Westbrook] shoulder a greater proportion of their team's offensive burden than Lin has this season, and Lin's offensive efficiency is considerably better. The only players in the NBA to use more than 30 percent of team possessions and post better efficiency marks than Lin? Heat teammates [LeBron James and Dwyane Wade]. So, offensively, Lin is in elite company.

However, as Paine continues, “It’s also fair to point out Lin’s propensity for turnovers. This season, 21.8 percent of Lin's individual possessions have ended with him committing a turnover, 16th most among guards with at least 159 minutes. Lin's turnovers tend to come in bunches, too. He already has two eight-turnover games, to go with three more games in which he turned the ball over six times”. Lin himself concedes as much. After the Knicks' win against Sacramento, Lin said his greatest challenge thus far was to find ways to be efficient with the minutes given and to avoid turnovers. This is especially noteworthy in the Knicks' following game, which they lost to New Orleans 89-85, when Lin had nine turnovers, tying for the most in the 2011/12 season.

Inspired by these and other comments, the purpose of this note is to provide a timely and comprehensive assessment of Jeremy Lin's basketball playing efficiency. Fortunately, research in sports economics has recently embraced econometric and mathematical methods for the study of sporting efficiency, an important development as these empirical relationships are useful for making decisions on, among other things, hiring, play positions, and salaries. Beginning with work by Scully (1974) on baseball and Thomas et al. (1979) and Zak et al. (1979) on basketball, successive works have estimated team production functions in an effort to quantify the relationship between sporting inputs and sporting success. Subsequently applied to many sports, including soccer (Dawson et al. 2000a, 2000b; Carmichael et al. 2001; Hass 2003; Espitia-Escuer and Garcia-Cebrian 2004), rugby league (Carmichael and Thomas 1995; Barros and Leach 2006a, 2006b), baseball (Mazur 1994; Ruggerio et al. 1996; Einholf 2004, Kang et al. 2007; Lewis et al. 2007), and American football (gridiron) (Hadley et al. 2000; Hofler and Payne 1996) of particular relevance are those concerning basketball. These include Chatterjee et al. (1994), Hofler and Payne (1997, 2006), Berri (1999), McGoldrick and Voeks (2005) and Lee and Berri (2008), Rimler et al. (2010). However, unlike nearly all of this research, we choose to focus on individual player efficiency. 
The remainder of the note is structured as follows. Section 2 briefly describes the conceptual framework and the data used in the analysis. Section 3 explains the methodology, and Section 4 reports the results. Section 5 concludes the paper.

\section{Conceptual framework and data specification}

To measure the efficiency of a player, we need to specify an appropriate production process in which measurable inputs transform into measurable outputs. For instance, Lee and Berri (2008) considered the number of basketball wins as an output, which in turn is dependent on inputs such as points per possession employed and the points surrendered per possession acquired. Likewise, Berri (1999) measured a player's value by considering inputs such as points, rebounds, and steals, etc. and including the number of team wins. This model suggests that the number of wins influences a player's efficiency or value. However, unlike individual sports where a win is largely dependent on an individual's performance, basketball is a team sport, which suggests that the performance of all players must be included in the production model to determine a win. In our framework, we measure a player's contribution based on his own inputs and outputs, rather than those of the team. This may or may not correspond with team success.

Consequently, our analysis measures the efficiency of point and shooting guards (collectively guards). The point guard and shooting guard, two of the five standard positions in a regulation basketball game are typically the team's best ball handlers and passers. The point guard is a position equivalent to that of the midfielder in soccer, the quarterback in American football (gridiron), the halfback in rugby league, or the centre in ice hockey, in that the player is responsible for directing plays and passing the ball as well as scoring. For this reason, the point guard should fully understand and implement the coach's game plan and the team's overall strategy and is a primary determinant of the team's ability to win games. By way of comparison, the shooting guard's main objective is to score points, but may also serve as the ball handler, exemplified, for example, by Kobe Bryant of the Los Angeles Lakers and Jason Terry of the Dallas Mavericks. Recent years have seen an increase in the number of shooting guards being point guards and vice-versa. Point guards as shooting guards include players like Derrick Rose of the Chicago Bulls and Russell Westbrook of the Oklahoma City Thunder. Because of the interchangeableness of the roles, it is difficult to ascertain which players are truly point guards and/or shooting guards, so our sample considers all guards. 
All our data are from the official NBA website (www.nba.com). We specify the outputs based on a player's overall contribution to game play. These are points per game (PPG) (scoring with field goals or free throws), rebounds per game (RPG) (gaining possession of the ball after a missed field goal or free throw), assists per game (APG) (passing the ball to a teammate in a way that leads to a score), steals per game (SPG) (legally causing a turnover to gain possession of the ball), and blocks per game (BPG) (legally deflecting a field goal attempt). These five outputs are positive outputs associated with superior guard performance, though the weighting or emphasis placed on each output will of course vary throughout the game. For instance, points are a better indicator of offensive play while steals are a better measure of defensive play. In addition, we include turnovers per game (TOPG), which is a negative or undesirable guard output, as this is associated with the team turning from offensive to defensive play. The single input in our model is minutes per game (MPG). Actual play in the NBA comprises 12-minute quarters in a 48 minute game, but after including half-time, timeouts, fouls, and close games, a basketball game typically lasts around 21/2 hours. Ideally, a guard would maximize the positive outputs and minimizing the negative output given the feasible resource limit of time in play.

Using this framework, we need to ensure that our dataset allows for an appropriate comparison. First, we include only guards in our analysis. This is because our behavioural assumption (i.e. the specification of inputs and outputs) differs markedly depending on the player's position and responsibilities, in turn depending on archetypical physical attributes and mental capabilities. This ensures we compare like with like. Second, we only include players who have played 19 games or more as a starter. We base this threshold on the number of games for which Lin has been a starter (that is, playing from the start of the game, and usually an indicator of the player's importance in the team). We only consider starters as it is only from when Jeremy Lin became a starter that he performed most outstandingly. Hence, of the 128 guards in the NBA, 62 are eligible for inclusion in our sample. Finally, as we focus on the Linsanity phenomenon that began in February 2012, we restrict ourselves to a cross-sectional analysis of the 2011/12 season.

Table 1. Selected descriptive statistics

\begin{tabular}{|c|c|c|c|c|c|c|c|}
\hline \multirow{3}{*}{ Statistic } & \multirow{3}{*}{$\begin{array}{l}\text { Input } \\
\text { MPG }\end{array}$} & \multicolumn{6}{|c|}{ Outputs } \\
\hline & & \multicolumn{5}{|c|}{ Positive } & \multirow{2}{*}{$\begin{array}{c}\text { Negative } \\
\text { TOPG }\end{array}$} \\
\hline & & PPG & RPG & APG & SPG & BPG & \\
\hline Mean & 31.682 & 13.827 & 3.355 & 4.427 & 1.177 & 0.286 & 2.148 \\
\hline Std. dev. & 4.224 & 5.104 & 0.938 & 2.565 & 0.506 & 0.223 & 0.957 \\
\hline
\end{tabular}




\begin{tabular}{lrrrrrrr} 
Coef. of variation & 0.133 & 0.369 & 0.280 & 0.579 & 0.430 & 0.780 & 0.446 \\
Minimum & 22.400 & 3.200 & 1.500 & 0.300 & 0.400 & 0.030 & 0.400 \\
First quartile & 29.450 & 10.500 & 2.700 & 2.200 & 0.800 & 0.133 & 1.600 \\
Median & 32.600 & 13.500 & 3.300 & 4.100 & 1.000 & 0.265 & 2.000 \\
Third quartile & 35.100 & 17.100 & 3.775 & 6.150 & 1.500 & 0.350 & 2.700 \\
Maximum & 38.900 & 29.000 & 5.700 & 11.100 & 2.500 & 1.300 & 5.100 \\
\hline
\end{tabular}

Notes: MPG - minutes per game, APG - assists per game, PPG - points per game, SPG - steals per game, RPG - rebounds per game, BPG - blocks per game, - TOPG turnovers per game.

Table 1 provides selected descriptive statistics for the guard input and outputs as sampled. As shown, the typical NBA starting guard is on the court for 31.68 minutes, scoring 13.83 points, making 3.35 rebounds, providing 4.42 assists, 1.18 steals, and 0.29 blocks. The guard also turnovers the ball to the opposing team 2.15 times. Of the variables included, the most variable as measured by the coefficient of variation is blocks per game and the least variable is minutes per game. By way of comparison with the focus of our analysis, Jeremy Lin is in the upper quartiles for minutes (35.70), points (19.40), assists (8.40) and steals (2.40) per game. Less well, he is only in the next-to-upper quartile for rebounds per game (3.60) and the next-to-lower quartile for blocks per game (0.26). Most troublingly, Jeremy Lin also has the most turnovers (5.10) per game in the entire sample.

\section{Methodology}

We use a mathematical programming approach to calculate the productive efficiency of NBA starting guards, including Jeremy Lin. The mathematical programming approach seeks to evaluate the efficiency of a decision-making unit (here a player, but also an organisation or team) relative to other decision-making units in the same area (here other players, but also industries or sports). The most commonly employed version of this approach is a linear programming tool referred to as 'data envelopment analysis' (DEA). DEA essentially calculates the economic efficiency of our given player relative to the performance of other players producing the same outcomes, rather than against some theoretical or idealised standard of performance.

One obvious problem with DEA is that in contrast to the econometric approaches to efficiency measurement it is both nonparametric and nonstochastic. Thus, we make no accommodation for the types of bias resulting from environmental heterogeneity, external shocks, measurement error, and omitted variables. Consequently, we assess the entire deviation from the productive frontier as being the result of inefficiency. This may lead to either an under or over-statement of the level of inefficiency. However, there a number of benefits implicit in DEA that makes it attractive on a 
theoretical level. First, given its nonparametric basis, it is relatively easy to alter the specification of inputs and outputs and thereby the formulation of the production correspondence relating inputs to outputs. Second, when using the econometric approach, we impose considerable structure upon the data from stringent parametric form and distributional assumptions regarding both inefficiency and, in the case of stochastic frontiers, statistical noise. These considerations, and the natural emphasis of DEA on the notion of 'best-practice' performance, make it an attractive choice in our chosen context. More specifically, we employ Seiford and Zhu's (2002) data envelopment analysis (DEA) framework that deals with both desirable and undesirable outputs concurrently. Under basketball conditions, we can view individual efficiency in terms of the utilisation of ball possession with the aim of maximising points and other contributions while minimising the number of turnovers. This suggests increasing the desirable output $\left(Y^{g}\right)$ while reducing the undesirable output $\left(Y^{b}\right)$ which follows the linear monotone decreasing transformation in Seiford and Zhu (2002) based upon the classification invariance concept in Ali and Seiford (1990). Seiford and Zhu's (2002) approach helps preserve the linearity and convexity of the DEA model. Starting with the following DEA data domain:

$$
\left[\begin{array}{c}
Y \\
-X
\end{array}\right]=\left[\begin{array}{c}
Y^{g} \\
Y^{b} \\
-X
\end{array}\right]
$$

where $Y^{g}$ and $Y^{b}$ represent the corresponding desirable and undesirable outputs and $X$ represents the input. To increase $Y^{g}$ while reducing $Y^{b}$, Seiford and Zhu (2002) multiplied each undesirable output by negative one and then find a proper translation vector value $w$ to convert all negative undesirable outputs into positives $\left(Y^{-b}=-Y_{j}^{b}+w>0\right)$ which results in the following domain:

$$
\left[\begin{array}{c}
Y \\
-X
\end{array}\right]=\left[\begin{array}{c}
Y^{g} \\
Y^{-b} \\
-X
\end{array}\right]
$$

Based upon (2), we then use Banker et al. (1984) model to modify the following linear program: 
$\max \theta$

$$
\begin{array}{ll}
\text { s.t. } & \sum_{j=1}^{n} z_{j} y_{j}^{g} \geq \theta y_{o}^{g}, \\
& \sum_{j=1}^{n} z_{j} y_{j}^{-b} \geq \theta y_{o}^{-b}, \\
& \sum_{j=1}^{n} z_{j} x_{j} \leq x_{o}, \\
& \sum_{j=1}^{n} z_{j}=1, \\
& z_{j} \geq 0, \quad j=1, \ldots, n .
\end{array}
$$

Here, $\theta$ is the efficiency score of the DMU, $Y^{g}$ and $Y^{b}$ are the $j$-th desirable and undesirable outputs, respectively, $x_{j}$ is the $j$-th input and $z_{j}$ is the weight of $j$-th player, and $x_{o}$ and $y_{o}$ represent the input and output vectors for all players.

To investigate better the impact of undesirable outputs on starting guard productive efficiency, we model two separate cases. All cases have the same set of inputs, but different sets of outputs. In the first case, we restrict the outputs to only the desirable outputs (PPG, RPG, APG, SPG, and BPG). The second case takes into account both desirable and undesirable outputs; that is, we also include TOPG.

\section{Results}

Table 2 provides the efficiency scores and ranks for each player using the above method. An efficiency score of one indicates that the player is efficient and therefore lies on the best-practice productive frontier. Note that the production frontier reflects different combinations of the inputs with the weights determined by the sample data, such that different players on the frontier are engaging in different productively efficient behaviour. 
Table 2. Efficiency scores by player

\begin{tabular}{|c|c|c|c|c|c|c|c|c|c|}
\hline Player & $\begin{array}{c}\text { Without } \\
\text { undesirable } \\
\text { output }\end{array}$ & Rank & $\begin{array}{c}\text { With } \\
\text { undesirable } \\
\text { output }\end{array}$ & Rank & Player & $\begin{array}{c}\text { Without } \\
\text { undesirable } \\
\text { output }\end{array}$ & Rank & $\begin{array}{c}\text { With } \\
\text { undesirable } \\
\text { output }\end{array}$ & Rank \\
\hline Anthony Parker, CLE & 1.228 & 34 & 1.002 & 28 & Luke Ridnour, MIN & 1.624 & 61 & 1.061 & 48 \\
\hline Arron Afflalo, DEN & 1.619 & 60 & 1.012 & 31 & Marco Belinelli, NOH & 1.615 & 59 & 1.057 & 46 \\
\hline Brandon Jennings, MIL & 1.193 & 32 & 1.028 & 38 & Marcus Thornton, SAC & 1.315 & 47 & 1.000 & 1 \\
\hline Brandon Knight, DET & 1.398 & 53 & 1.211 & 62 & Mario Chalmers, MIA & 1.303 & 46 & 1.148 & 59 \\
\hline Chauncey Billups, LAC & 1.259 & 40 & 1.058 & 47 & MarShon Brooks, NJN & 1.330 & 49 & 1.178 & 60 \\
\hline Chris Paul, LAC & 1.000 & 1 & 1.000 & 1 & Mike Conley, MEM & 1.000 & 1 & 1.000 & 1 \\
\hline D.J. Augustin, CHA & 1.212 & 33 & 1.076 & 51 & Monta Ellis, GSW & 1.105 & 27 & 1.102 & 55 \\
\hline Daequan Cook, OKC & 1.000 & 1 & 1.000 & 1 & Nick Young, WAS & 1.252 & 37 & 1.000 & 1 \\
\hline Darren Collison, IND & 1.391 & 52 & 1.086 & 53 & Paul George, IND & 1.000 & 1 & 1.000 & 1 \\
\hline Delonte West, DAL & 1.000 & 1 & 1.000 & 1 & Raja Bell, UTA & 1.360 & 51 & 1.019 & 34 \\
\hline DeMar DeRozan, TOR & 1.493 & 57 & 1.089 & 54 & Rajon Rondo, BOS & 1.000 & 1 & 1.000 & 1 \\
\hline Derek Fisher, LAL & 1.437 & 56 & 1.035 & 41 & Randy Foye, LAC & 1.526 & 58 & 1.039 & 42 \\
\hline Deron Williams, NJN & 1.001 & 20 & 1.001 & 27 & Ray Allen, BOS & 1.645 & 62 & 1.051 & 44 \\
\hline Derrick Rose, CHI & 1.000 & 1 & 1.000 & 1 & Raymond Felton, POR & 1.283 & 45 & 1.197 & 61 \\
\hline DeShawn Stevenson, NJN & 1.000 & 1 & 1.000 & 1 & Ricky Rubio, MIN & 1.000 & 1 & 1.000 & 1 \\
\hline Devin Harris, UTA & 1.074 & 26 & 1.011 & 30 & Rodney Stuckey, DET & 1.315 & 47 & 1.062 & 49 \\
\hline Dwyane Wade, MIA & 1.000 & 1 & 1.000 & 1 & Ronnie Brewer, CHI & 1.245 & 36 & 1.000 & 1 \\
\hline Gerald Henderson, CHA & 1.264 & 42 & 1.083 & 52 & Russell Westbrook, OKC & 1.019 & 22 & 1.019 & 34 \\
\hline Jameer Nelson, ORL & 1.262 & 41 & 1.115 & 57 & Shaun Livingston, MIL & 1.000 & 1 & 1.000 & 1 \\
\hline Jared Dudley, PHX & 1.126 & 28 & 1.000 & 1 & Stephen Curry, GSW & 1.018 & 21 & 1.016 & 33 \\
\hline Jarrett Jack, NOH & 1.269 & 43 & 1.108 & 56 & Steve Nash, PHX & 1.000 & 1 & 1.000 & 1 \\
\hline Jason Kidd, DAL & 1.000 & 1 & 1.000 & 1 & Tony Allen, MEM & 1.000 & 1 & 1.000 & 1 \\
\hline Jason Richardson, ORL & 1.255 & 38 & 1.034 & 40 & Tony Parker, SAS & 1.021 & 23 & 1.006 & 29 \\
\hline Jeff Teague, ATL & 1.231 & 35 & 1.040 & 43 & Ty Lawson, DEN & 1.170 & 31 & 1.067 & 50 \\
\hline Jeremy Lin, NYK & 1.000 & 1 & 1.000 & 1 & Tyreke Evans, SAC & 1.039 & 25 & 1.023 & 37 \\
\hline Jodie Meeks, PHI & 1.282 & 44 & 1.000 & 1 & Vince Carter, DAL & 1.000 & 1 & 1.000 & 1 \\
\hline Joe Johnson, ATL & 1.418 & 55 & 1.014 & 32 & Wesley Matthews, POR & 1.412 & 54 & 1.000 & 1 \\
\hline John Wall, WAS & 1.000 & 1 & 1.000 & 1 & No. of efficient players & 18 & - & 26 & - \\
\hline Jose Calderon, TOR & 1.149 & 30 & 1.000 & 1 & Mean & 1.192 & - & 1.037 & - \\
\hline Jrue Holiday, PHI & 1.338 & 50 & 1.140 & 58 & Std. dev. & 0.193 & - & 0.053 & - \\
\hline Kevin Martin, HOU & 1.258 & 39 & 1.022 & 36 & Minimum & 1.000 & - & 1.000 & - \\
\hline Kobe Bryant, LAL & 1.000 & 1 & 1.000 & 1 & First quartile & 1.000 & - & 1.000 & - \\
\hline Kyle Lowry, HOU & 1.000 & 1 & 1.000 & 1 & Median & 1.182 & - & 1.013 & - \\
\hline Kyrie Irving, CLE & 1.028 & 24 & 1.028 & 38 & Third quartile & 1.312 & - & 1.058 & - \\
\hline Landry Fields, NYK & 1.136 & 29 & 1.051 & 44 & Maximum & 1.645 & - & 1.211 & - \\
\hline
\end{tabular}


For example, one player may be efficient because of a relatively large number of defensive plays while another may be efficient because of their offensive play in scoring points. In general, a larger number of outputs imply greater opportunity for efficient behaviour, and in turn, more players defining the frontier. A player with an efficiency score more than one indicates that a player can improve his efficiency by modifying his production process in order to reach the production frontier along the closest path defined by the direction vector.

If we consider the model including only desirable outputs, 18 of the 62 players ( 29 percent) are efficient with a mean level of inefficiency of 19.2 percent $(=1.192-1)$. As our model is outputorientated, focus is on the equiproportionate augmentation of outputs relative to inputs. Accordingly, the average NBA starting guard would have to increase his desirable outputs by 19.2 percent to place him on the best-practice productive frontier. The most inefficient player is Ray Allen (1.645 or 64.5 percent inefficient). However, when we include undesirable output (turnovers) in the model, 26 players are efficient, including all of the players judged efficient with only desirable outputs. By considering undesirable outputs in the model, eight additional players are efficient largely because while their input and desirable output numbers may not be as high, their undesirable output is sufficiently low to place them on the frontier. The mean level of efficiency is lower when we take account of the undesirable outputs, with the typical NBA point guard being 3.7 percent inefficient relative to best practice.

This can work both ways. For example, Arron Affalo's efficiency substantially improved after we considered the undesirable output from 61.9 percent inefficient to just 1.2 percent inefficient, increasing his rank from 60th to 31st. In contrast, the efficiency of Tyreke Evans improved in terms of level (3.9 to 2.3 percent) but his ranking fell (from 25th to 37th). Similar to Färe et al. (1989), our results confirm the same findings that standard DEA method fails to credit DMUs for undesirable output reduction, and this potentially distorts the true measured efficiency. We can see that Jeremy Lin is fully efficient in both models. 
Table 3. Efficiency improvements for inefficient players

\begin{tabular}{|c|c|c|c|c|c|c|c|}
\hline & MPG & PPG & RPG & $\mathrm{APG}$ & SPG & BPG & TOPG \\
\hline Anthony Parker, CLE & - & 0.379 & 0.397 & - & 0.105 & - & - \\
\hline Arron Afflalo, DEN & 0.616 & - & 1.440 & - & 0.346 & - & - \\
\hline Brandon Jennings, MIL & 1.018 & - & - & - & 0.286 & - & - \\
\hline Brandon Knight, DET & - & - & - & - & 0.708 & 0.126 & - \\
\hline Chauncey Billups, LAC & - & - & 0.874 & - & 1.055 & 0.368 & - \\
\hline D.J. Augustin, CHA & - & - & 0.056 & - & 0.654 & 0.041 & - \\
\hline Darren Collison, IND & 1.882 & - & - & - & 0.099 & - & - \\
\hline DeMar DeRozan, TOR & 1.299 & - & - & - & 0.211 & - & - \\
\hline Derek Fisher, LAL & - & 1.044 & 0.492 & - & - & 0.006 & - \\
\hline Deron Williams, NJN & 0.853 & - & - & - & - & 0.180 & 1.025 \\
\hline Devin Harris, UTA & - & - & 1.289 & - & 0.326 & - & - \\
\hline Gerald Henderson, CHA & 0.265 & - & - & - & 0.052 & 0.023 & - \\
\hline Jameer Nelson, ORL & - & - & - & - & 0.429 & 0.080 & - \\
\hline Jarrett Jack, NOH & 0.760 & - & - & - & 0.886 & - & - \\
\hline Jeff Teague, ATL & 0.958 & 3.304 & 1.795 & - & - & - & - \\
\hline Joe Johnson, ATL & 1.405 & - & - & - & 0.627 & - & - \\
\hline Jrue Holiday, PHI & 1.789 & 0.081 & - & - & - & - & - \\
\hline Kevin Martin, HOU & - & - & 0.315 & - & 0.473 & 0.346 & - \\
\hline Kyrie Irving, CLE & - & - & 0.114 & - & 0.574 & 0.463 & 0.257 \\
\hline Landry Fields, NYK & - & 1.854 & - & - & 0.060 & 0.179 & - \\
\hline Luke Ridnour, MIN & 3.224 & - & 0.548 & - & 0.181 & - & - \\
\hline Marco Belinelli, NOH & 1.942 & - & - & - & 0.109 & 0.092 & - \\
\hline Mario Chalmers, MIA & - & 0.417 & 0.186 & - & - & 0.102 & - \\
\hline MarShon Brooks, NJN & - & - & - & - & 0.079 & - & - \\
\hline Monta Ellis, GSW & - & - & 0.693 & - & - & 0.026 & - \\
\hline Raja Bell, UTA & - & - & 1.300 & - & 0.302 & 0.304 & - \\
\hline Randy Foye, LAC & 1.819 & 0.469 & 1.104 & - & 0.027 & - & - \\
\hline Ray Allen, BOS & 2.931 & - & - & - & 0.082 & - & - \\
\hline Raymond Felton, POR & - & 2.941 & 0.617 & - & - & - & - \\
\hline Rodney Stuckey, DET & - & - & - & - & 0.455 & 0.161 & - \\
\hline Russell Westbrook, OKC & - & - & - & - & - & 0.459 & 0.271 \\
\hline Stephen Curry, GSW & - & - & - & - & - & 0.172 & - \\
\hline Tony Parker, SAS & - & - & 0.448 & - & 0.017 & 0.417 & - \\
\hline Ty Lawson, DEN & - & - & - & - & 0.473 & 0.081 & - \\
\hline Tyreke Evans, SAC & 1.424 & - & - & - & 0.371 & - & - \\
\hline
\end{tabular}

Table 3 details the potential improvements for each inefficient player needed to achieve overall efficiency using the model including the undesirable output of turnovers per game (the model more favourable to players). This shows the percentage changes required to reduce the undesirable output or/and increase the desirable outputs relative to the level of input. For example, Deron Williams can improve his overall efficiency by increasing his minutes played (MPG) by 14.7 percent (= $1-0.853)$, reducing his turnovers (TOPG) by 2.5 percent $(=1-$ 1.025) and increasing his blocks (BPG) by 82 percent (= $1-0.180)$. Alternatively, Anthony 
Parker could maintain the same level of input in terms of minutes played, and focus instead on increasing his outputs in terms of points (by 62.1 percent), rebounds (by 60.3 percent) and steals (by 89.5 percent). Obviously, some of these improvements may be feasible in theory, but infeasible in practice, given the player's endowments and game conditions.

Table 4 provides information on the benchmark players used to determine the efficiency improvements needed for the inefficient players in Tables 2 and 3. Note that the benchmark players are not equally weighted. For example, Deron Williams' benchmarks (percentage of target needed) are Derrick Rose (77.8 percent), Chris Paul (10.3 percent), Jeremy Lin (10.7 percent), and Steve Nash 1.2 percent). Note $77.8+10.3+10.7+1.2=100$ percent. Clearly, of the benchmark players needed for Deron Williams to improve his performance, the most important to observe and target is Derrick Rose as his (efficient) combination of inputs and outputs is closest to Deron Williams' existing (inefficient) combination and therefore the easiest to imitate in terms of an efficiency improvement.

While any efficient player can potentially serve as a benchmark, in practice only a smaller subset typically comprise the optimal benchmark solution. This is quite telling in that the most important point guards in terms of defining efficiency improvements (number of player benchmarks set) are Chris Paul (29), Dwayne Wade (22), Jared Dudley (16), Daequan Cook (14) and Jose Calderon (14). We could then say with some justification that the productive behaviour of these five point guards epitomises the NBA at its best. Surprisingly, Jeremy Lin with just four benchmarks accounts for only a small percentage of the optimal lambdas, suggesting that in both absolute and relative terms his unique performance as defined by Linsanity, while technically efficient, is neither feasible nor desirable for the majority of inefficient point guards in the NBA. The exceptions are Deron Williams (10.7 percent), Russell Westbrook (22.6 percent), Stephen Curry (5.9 percent), and Monta Ellis (1.6 percent). This possibly emphasises the uniqueness of his productive solution, encompassing as it does exemplary performance in points, assists and steals, moderate performance in rebounds and blocks, and rather lacklustre performance in turnovers. 
Table 4. Optimal lambdas with benchmarks for inefficient players

\begin{tabular}{|c|c|}
\hline Inefficient player & Benchmark players \\
\hline Anthony Parker, CLE & 0.055 Jose Calderon, TOR; 0.389 Delonte West, DAL; 0.286 Daequan Cook, OKC; 0.271 DeShawn Stevenson, NJN. \\
\hline Arron Afflalo, DEN & 0.065 Chris Paul, LAC; 0.038 Nick Young, WAS; 0.729 Jared Dudley, PHX; 0.169 Jodie Meeks, PHI. \\
\hline Brandon Jennings, MIL & 0.172 Dwyane Wade, MIA; 0.561 Chris Paul, LAC; 0.051 Marcus Thornton, SAC; 0.157 Nick Young, WAS; 0.059 Jared Dudley, PHX. \\
\hline Brandon Knight, DET & 0.347 Chris Paul, LAC; 0.405 Jared Dudley, PHX; 0.031 Rajon Rondo, BOS; 0.166 Paul George, IND; 0.051 Jose Calderon, TOR. \\
\hline Chauncey Billups, LAC & 0.300 Dwyane Wade, MIA; 0.315 Chris Paul, LAC; 0.123 Jodie Meeks, PHI; 0.262 Daequan Cook, OKC. \\
\hline D.J. Augustin, CHA & 0.320 Chris Paul, LAC; 0.050 Steve Nash, PHX; 0.280 Jose Calderon, TOR; 0.350 Delonte West, DAL. \\
\hline Darren Collison, IND & 0.087 Dwyane Wade, MIA; 0.085 Chris Paul, LAC; 0.119 Jared Dudley, PHX; 0.460 Jose Calderon, TOR; 0.249 Daequan Cook, OKC. \\
\hline DeMar DeRozan, TOR & 0.066 Dwyane Wade, MIA ; 0.014 Chris Paul, LAC; 0.573 Marcus Thornton, SAC; 0.114 Nick Young, WAS; 0.233 Jared Dudley, PHX \\
\hline Derek Fisher, LAL & 0.097 Chris Paul, LAC; 0.146 Jose Calderon, TOR; 0.261 Delonte West, DAL; 0.495 DeShawn Stevenson, NJN. \\
\hline Deron Williams, NJN & 0.778 Derrick Rose, CHI; 0.103 Chris Paul, LAC; 0.107 Jeremy Lin, NYK; 0.012 Steve Nash, PHX. \\
\hline Devin Harris, UTA & 0.095 Dwyane Wade, MIA; 0.074 Steve Nash, PHX; 0.071 Jose Calderon, TOR; 0.687 Delonte West, DAL; 0.073 Daequan Cook, OKC. \\
\hline Gerald Henderson, CHA & 0.036 Dwyane Wade, MIA; 0.055 Chris Paul, LAC; 0.050 Marcus Thornton, SAC; 0.858 Jared Dudley, PHX. \\
\hline Jameer Nelson, ORL & 0.100 Dwyane Wade, MIA; 0.083 Chris Paul, LAC; 0.509 Jose Calderon, TOR; 0.161 Delonte West, DAL; 0.147 Daequan Cook, OKC. \\
\hline Jarrett Jack, NOH & 0.191 Dwyane Wade, MIA; 0.454 Chris Paul, LAC; 0.101 Jared Dudley, PHX; 0.249 Jose Calderon, TOR; 0.006 Daequan Cook, OKC. \\
\hline Jeff Teague, ATL & 0.168 Dwyane Wade, MIA; 0.370 Chris Paul, LAC; 0.295 Paul George, IND; 0.167 Daequan Cook, OKC. \\
\hline Joe Johnson, ATL & 0.024 Dwyane Wade, MIA; 0.314 Chris Paul, LAC; 0.492 Marcus Thornton, SAC; 0.151 Nick Young, WAS; 0.020 Jared Dudley, PHX. \\
\hline Jrue Holiday, PHI & 0.514 Chris Paul, LAC; 0.185 Wesley Matthews, POR; 0.167 Paul George, IND; 0.024 Jodie Meeks, PHI; 0.110 Daequan Cook, OKC. \\
\hline Kevin Martin, HOU & 0.202 Dwyane Wade, MIA; 0.146 Chris Paul, LAC; 0.523 Nick Young, WAS; 0.129 Jodie Meeks, PHI. \\
\hline Kyrie Irving, CLE & 0.671 Dwyane Wade, MIA; 0.150 Steve Nash, PHX; 0.179 Delonte West, DAL. \\
\hline Landry Fields, NYK & 0.220 Jared Dudley, PHX; 0.610 Paul George, IND; 0.141 Jose Calderon, TOR; 0.029 Daequan Cook, OKC. \\
\hline Luke Ridnour, MIN & 0.065 Dwyane Wade, MIA; 0.320 Chris Paul, LAC; 0.133 Jose Calderon, TOR; 0.482 Daequan Cook, OKC. \\
\hline Marco Belinelli, NOH & 0.022 Chris Paul, LAC; 0.362 Marcus Thornton, SAC; 0.011 Jared Dudley, PHX; 0.605 Jodie Meeks, PHI. \\
\hline Mario Chalmers, MIA & 0.358 Chris Paul, LAC; 0.211 Tony Allen, MEM; 0.162 Delonte West, DAL; 0.269 Daequan Cook, OKC. \\
\hline MarShon Brooks, NJN & 0.104 Kobe Bryant, LAL; 0.061 Dwyane Wade, MIA; 0.150 Chris Paul, LAC; 0.623 Jared Dudley, PHX; 0.062 Paul George, IND. \\
\hline Monta Ellis, GSW & 0.390 Kobe Bryant, LAL; 0.080 Dwyane Wade, MIA; 0.151 Derrick Rose, CHI; 0.364 Chris Paul, LAC; 0.016 Jeremy Lin, NYK. \\
\hline Raja Bell, UTA & 0.030 Chris Paul, LAC; 0.048 Jose Calderon, TOR; 0.055 Delonte West, DAL; 0.867 Daequan Cook, OKC. \\
\hline Randy Foye, LAC & 0.301 Dwyane Wade, MIA; 0.153 Jose Calderon, TOR; 0.546 Daequan Cook, OKC. \\
\hline
\end{tabular}




\begin{tabular}{ll}
\hline Inefficient player & Benchmark players \\
\hline Ray Allen, BOS & 0.223Chris Paul, LAC; 0.019 Marcus Thornton, SAC; 0.415 Nick Young, WAS; 0.111 Jared Dudley, PHX; 0.231 Jodie Meeks, PHI \\
Raymond Felton, POR & 0.067 Dwyane Wade, MIA; 0.456 Chris Paul, LAC; 0.132 Steve Nash, PHX; 0.119 Jose Calderon, TOR; 0.226 Delonte West, DAL. \\
Rodney Stuckey, DET & 0.170 Dwyane Wade, MIA; 0.382 Chris Paul, LAC; 0.324 Nick Young, WAS; 0.022 Jared Dudley, PHX; 0.103 Jodie Meeks, PHI. \\
Russell Westbrook, OKC & 0.319 Kobe Bryant, LAL; 0.445 Dwyane Wade, MIA; 0.226 Jeremy Lin, NYK; 0.003 Kyle Lowry, HOU; 0.007 Paul George, IND. \\
Stephen Curry, GSW & 0.357 Dwyane Wade, MIA; 0.048 Chris Paul, LAC; 0.059 Jeremy Lin, NYK; 0.069 Steve Nash, PHX; 0.123 Rajon Rondo, BOS; 0.344 \\
Tony Parker, SAS & Delonte West, DAL. \\
Ty Lawson, DEN & 0.569 Chris Paul, LAC; 0.034 Jared Dudley, PHX; 0.145 Rajon Rondo, BOS; 0.180 Paul George, IND; 0.072 Jose Calderon, TOR. \\
Tyreke Evans, SAC & 0.121 Kobe Bryant, LAL; 0.148 Dwyane Wade, MIA; 0.425 Kyle Lowry, HOU; 0.027 Jared Dudley, PHX; 0.279 Paul George, IND. \\
\hline
\end{tabular}




\section{Concluding remarks}

This note examined the individual player performance of starting point guards in the NBA during the 2011/12 season, a period personified by the Linsanity phenomena. Using DEA, we measured the productive efficiency of 62 guards using an input-output specification encompassing both desirable and undesirable inputs. The results indicate that between 29 and 42 percent of NBA guards are fully efficient, including Jeremy Lin, with a mean inefficiency of 3.7 and 19.2 percent. However, while the phenomena that is Jeremy Lin and that spawned Linsanity is technically efficient, he seldom serves as a benchmark for inefficient players, at least when compared with players such as Chris Paul and Dwayne Wade. This necessarily reinforces the uniqueness of Jeremy Lin's productive behaviour and perhaps highlights why his unique style of play, encompassing individual brilliance, unselfish play, and team leadership, is of such broad public appeal.

Of course, the analysis does have some limitations and these provide useful directions for future research. First, while it was not possible in this note to test the robustness of the results with respect to the input-output specification, it is likely that a smaller number of outputs would mean that fewer players define the efficient frontier. With some qualifications, this could more finely distinguish between efficient and inefficient players given that the broad specification used in this analysis permits such a wide range of potentially productive behaviour. Second, we focused only on individual player efficiency compared with the more common analysis of team-level efficiency with its natural focus on win and losses. One future direction would be to integrate these two hitherto separate areas such that individual player efficiency would nest within team efficiency in much the same manner as the performance of a business division or group nests with overall corporate performance. 


\section{References}

Adubato, S. (2012). Leadership lessons we can take from "Linsanity". Retrieved from http://www.nj.com/business/index.ssf/2012/02/adubato_leadership_lessons_we.html on February 19, 2012.

Ali, A. I., Seiford, L. M., (1990). Translation invariance in data envelopment analysis. Operations Research Letters 9, 403-405.

Banker, R.D., Charnes, A., Cooper, W.W., (1984). Some models for estimating technical and scale inefficiencies in data envelopment analysis. Management Science 30, 1078-1092.

Barros, C. P., Leach, S. (2006a). Analyzing the performance of the English FA Premier League with an econometric frontier model. Journal of Sports Economics, 7, 391-407.

Barros, C. P., Leach, S. (2006b). Performance evaluation of the English premier football league with data envelopment analysis. Applied Economics, 38, 1449-1458.

Berri, D. J. (1999). Who is "most valuable”? Measuring the player's production of wins in the National Basketball Association. Managerial and Decision Economics, 20, 411-427.

Carmichael, F., Thomas, D. (1995). Production and efficiency in team sports: An investigation of rugby league football. Applied Economics, 27, 859-869.

Carmichael, F., Thomas, D., Ward, R. (2001). Production and efficiency in association football. Journal of Sports Economics, 2, 228-243.

Chatterjee, S., Campbell, M. R., Wiseman, F. (1994). Take that jam! An analysis of winning percentage for NBA teams. Managerial \& Decision Economics, 15, 521-535.

Crescenzo, B. (2012). Finding the Jeremy Lin on Your Team. Retrieved on http://www.entrepreneur.com/article/222849 on 16 February 2012.

Dawson, P., Dobson, S., Gerrard, B. (2000a). Stochastic frontiers and the temporal structure of managerial efficiency in English soccer. Journal of Sports Economics, 1, 341-362. 
Dawson, P., Dobson, S., Gerrard, B. (2000b). Estimating coaching efficiency in professional team sports: Evidence from English association football. Scottish Journal of Political Economy, 47, 399-421.

Einolf, K. W. (2004). Is winning everything? A data envelopment analysis of major league baseball and the National Football League. Journal of Sports Economics, 5, 127-151.

Espitia-Escuer, M., \& García-Cebrián, L. I. (2004). Measuring the efficiency of Spanish first-division soccer teams. Journal of Sports Economics, 5, 329-346.

Färe, R., Grosskopf, S., Lovell, C.A.K., Pasurka, C., (1989). Multilateral productivity comparisons when some outputs are undesirable: a nonparametric approach. The Review of Economics and Statistics, 71, 90-98.

Gorrell, P. (2012). What business can learn from the Jeremy Lin story. Retrieved from http://www.huffingtonpost.com/paul-gorrell-phd/what-business-can-learn-f_2 b 1281922.html on 16 February 2012.

Hadley, L., Poitras, M., Ruggiero, J., Knowles, S. (2000). Performance evaluation of National Football League teams. Managerial and Decision Economics, 21, 63-70.

Hass, D. J. (2003). Productive efficiency of English football teams: A data envelopment analysis approach. Managerial and Decision Economics, 24, 403-410.

Hofler, R. A., Payne, J. E. (1996). How close to their offensive potential do National Football League teams play? Applied Economics Letters, 3, 743-747.

Hofler, R. A., \& Payne, J. E. (1997). Measuring efficiency in the National Basketball Association. Economics Letters, 55, 293-299.

Hofler, R., Payne, J. (2006). Efficiency in the National Basketball Association: A stochastic production frontier approach with panel data. Managerial and Decision Economics, 27, 279-285. 
Jackson, E. (2012). Just Lin, Baby! 10 Lessons Jeremy Lin Can Teach Us Before We Go To Work Monday Morning. Retrieved from http://www.forbes.com/sites/ericjackson/2012/02/11/9-lessonsjeremy-lin-can-teach-us-before-we-go-to-work-monday-morning/ on 11 February 2012.

Kang, J. H., Lee, Y. H., Sihyeong, K. S. (2007). Evaluating management efficiency of Korean Professional Baseball teams using data envelopment analysis. International Journal of Sport and Health Science, 5, 125-134.

Lee, Y.H. Berri, D. 2008. A Re-examination of Production functions and Efficiency estimates for the National Basketball Association. Scottish Journal of Political Economy, 55, 51-66.

Lewis, H. F., Sexton, T. R., Lock, K. A. (2007). Player salaries, organization efficiency, and competitiveness in major league baseball. Journal of Sports Economics, 8, 266-294.

Mazur, M. J. (1994). Evaluating the relative efficiency of baseball players. In Charnes, A. et al. (Eds.), Data envelopment analysis: Theory, methodology, and application (pp. 369-391). Dordrecht, the Netherlands: Kluwer Academic.

McGoldrick, K. M., Voeks, L. (2005). We got game! An analysis of win/loss probability and efficiency differences between the NBA and WNBA. Journal of Sports Economics, 6, 5-23.

Paine, N. (2012). Lin’s game still has flaws, but stats show his rise to stardom is no fluke. Retrieved from http://sportsillustrated.cnn.com/2012/basketball/nba/02/16/jeremy.lin.knicks/index.html on 16 February 2012.

Rimler, M.S., Song S-H, Yi, D.T. (2010). Estimating Production Efficiency in Men’s NCAA College Basketball: A Bayesian Approach. Journal of Sports Economics, 11, 287-315.

Ruggiero, J., Hadley, L., Gustafson, E. (1996). Technical efficiency in Major League Baseball. In J. Fizel, E. Gustafson, L. Hadley (Eds.), Baseball economics: Current research (pp. 191-200). Westport, CT: Greenwood, Praeger. 
Scully, G. W. (1974). Pay and performance in Major League Baseball. The American Economic Review, 64, 915-930.

Seiford, L. M., Zhu, J. (2002). Modeling undesirable factors in efficiency evaluation. European Journal of Operational Research, 142, 16-20.

Thomas A. Zak, Cliff J. Huang and John J. Siegfried, (1979). Production Efficiency: The Case of Professional Basketball, The Journal of Business. 52, pp. 379-392.

Zak, T. A., Huang, C. J. Siegfried, J. J. (1979). Production Efficiency: The Case of Professional Basketball. The Journal of Business, 52, 379-392. 